\title{
Dual receptor blockade by bosentan: clinical experience in treatment of pulmonary hypertension
}

This article was published in the following Dove Press journal:

Journal of Receptor, Ligand and Channel Research

20 November 2010

Number of times this article has been viewed

\author{
Susana Hoette ${ }^{1,2}$ \\ Dermot S O'Callaghan ${ }^{2}$ \\ Carlos Jardim' \\ Rogerio Souza' \\ 'Pulmonary Circulation Unit, \\ Pulmonary Department, Heart \\ Institute, University of São Paulo \\ Medical School, Sao Paulo, Brazil; \\ ${ }^{2}$ Hôpital Antoine Béclère, Université \\ Paris Sud, Orsay, France
}

\begin{abstract}
Pulmonary hypertension is characterized by an increase in mean pulmonary arterial pressure and right ventricular overload. Endothelin-1 (ET-1) is a potent vasoconstrictor with an important role in the pathogenesis of pulmonary hypertension. In addition to its vasoconstrictive action, ET-1 also stimulates cell proliferation, fibrosis, and inflammation. The blockade of both receptors involved in the action of ET-1 is beneficial in the treatment of pulmonary hypertension. The use of endothelin dual receptor blockade leads to improvements in quality of life, functional capacity, and pulmonary hemodynamics in affected patients. This article reviews the importance of ET-1 in the pathogenesis of pulmonary hypertension and demonstrates the benefits of blockage of the action of ET-1 in this disease.
\end{abstract}

Keywords: pulmonary hypertension treatment, endothelin-1, endothelin receptor blockage, bosentan

\section{Introduction}

Pulmonary hypertension is characterized by an increase in mean pulmonary arterial pressure of more than $25 \mathrm{mmHg}$ leading to right ventricular overload. Patients usually present with dyspnea and angina with exercise, and syncope, and there is a significant impact on functional capacity and quality of life. ${ }^{1}$ Without treatment, right ventricular failure and death are the natural course of the disease.

Pulmonary arterial hypertension (PAH) is the term reserved for cases of pulmonary hypertension that are idiopathic, familial, drug or toxin-induced, or associated with other diseases, including connective tissue disease, human immunodeficiency virus (HIV) infection, portal hypertension, congenital heart disease, schistosomiasis, chronic hemolytic anemia, and pulmonary veno-occlusive disease. ${ }^{2}$ Pulmonary hypertension can develop secondary to left heart disease, hypoxia, and lung disease, chronic thromboembolic disease, and pulmonary hypertension with unclear multifactorial mechanisms (Table 1).

\section{Pulmonary arterial hypertension}

In the past 10 years, there have been significant improvements in understanding the pathophysiology of PAH. Typically, pathologic findings of PAH are medial and intimal thickening, characterized by proliferation of smooth muscle cells and development of plexiform lesions. The presence and role of inflammatory infiltrates surrounding the vascular lesions has been increasingly recognized in recent years. ${ }^{3}$ Nevertheless, endothelial dysfunction is one of the main pathophysiologic mechanisms associated with PAH development and progression, resulting in a decrease in vasodilatory and
Correspondence: Rogerio Souza R Afonso de Freitas, 415 Sao Paulo, Brazil 04006052

Tel +55 II3 0695695

Fax +55 II 130695695

Email rogerio.souza@incor.usp.br 
Table I Clinical classification of pulmonary hypertension

Pulmonary arterial hypertension
Idiopathic
Heritable
Drug- and toxin-induced
Associated with connective tissue disease, human immunodeficiency
infection, portal hypertension, congenital heart disease,
schistosomiasis, and chronic hemolytic anemia
Persistent pulmonary hypertension of the newborn
Pulmonary veno-occlusive disease and/or pulmonary capillary
hemangiomatosis
Pulmonary hypertension owing to left heart disease
Pulmonary hypertension owing to lung disease and/or hypoxia
Chronic thromboembolic pulmonary hypertension
Pulmonary hypertension with unclear multifactorial mechanisms
Myeloproliferative disorders, splenectomy
Sarcoidosis, pulmonary Langerhans cell histiocytosis
Glycogen storage disease, Gaucher's disease, thyroid disorders
Tumoral obstruction, fibrosing mediastinitis, chronic renal failure on
dialysis

Notes: Copyright $@ 2009$, American College of Cardiology. Adapted with permission from Simonneau G, Robbins IM, Beghetti M, et al. Updated clinical classification of pulmonary hypertension. J Am Coll Cardiol. 2009;54 (I Suppl S):S43-S54.

antiproliferative factors (prostacyclin, nitric oxide) and in an increase in vasoconstrictor and proliferative factors (endothelin-1). ${ }^{4}$ Endothelin is considered to be the most potent endogenous vasoconstrictor identified to date, and has a significant role in the pathogenesis of $\mathrm{PAH}^{.-7}$ In addition to its vasoconstrictive effects, endothelin is also known to stimulate cellular proliferation, to increase secretion of vascular endothelial growth factor (known for its angiogenic activity), and to promote cellular migration. ${ }^{8,9}$ Endothelin is also involved in promoting fibrosis and inflammation. ${ }^{10,11}$

Endothelin is mainly produced by endothelial cells, but other cells, including smooth muscle cells, fibroblasts, cardiomyocytes, and mesangial cells are involved in its production, although to a lesser extent. Endothelin is synthesized from the precursor, preproendothelin, which is cleaved into inactive proendothelin (usually referred to as bigendothelin). Bigendothelin is then converted into the active molecule by endothelin-converting enzymes. Three molecules have been described in humans, ie, endothelin-1 (ET-1), endothelin-2, and endothelin-3. The pulmonary circulation is the most important site of both production and clearance of ET-1. ${ }^{12}$ Endothelin-2 has minimal activity in the lung, and the role of endothelin-3 is less well understood. Pharmacologically, ET-1 is the most potent member of the endothelin family and is known to play a critical role in cell proliferation, fibrosis, and inflammation, all of which are relevant to the pathophysiology of PAH (see Figure 1).,4,13

ET-1 levels are markedly increased in pulmonary hypertension. In an experimental monocrotalin-induced rat model of PAH, ET-1 concentrations in lung perfusate and serum were significantly increased as compared with controls. ${ }^{7,14}$ Similar results were found in humans, with different studies demonstrating a significantly increased expression of ET-1 in lung and blood samples of patients with PAH as compared with controls. ${ }^{15-17}$ One study also demonstrated an increased gradient of ET-1 from the right ventricle to pulmonary venous blood in patients with PAH that was not present in patients with normal pulmonary artery pressures. These data suggest that there is an increased pulmonary production of ET-1 in patients with PAH. ${ }^{18}$ ET-1 was also significantly correlated with right atrial pressure, pulmonary artery oxygen saturation, and brain natriuretic peptide levels, which are known markers of severity and prognosis of PAH. ${ }^{17,19}$

ET-1 acts via two different receptors, endothelin receptor $\mathrm{A}\left(\mathrm{ET}_{\mathrm{A}}\right)$ and endothelin receptor $\mathrm{B}\left(\mathrm{ET}_{\mathrm{B}}\right) . \mathrm{ET}_{\mathrm{A}}$ receptors are found in greater quantity in the proximal pulmonary arteries, while $\mathrm{ET}_{\mathrm{B}}$ receptors increase in proportion in distal pulmonary arteries and are also present in venous smooth muscle cells. ${ }^{20}$ Endothelin receptors are G-protein-coupled receptors. When endothelin binds to the receptor, phospholipase $\mathrm{C}$ is activated and diacylglycerol and inositol triphosphate are released from the plasma membrane. Inositol triphosphate activates release of calcium from the endoplasmic reticulum and this contributes to smooth muscle cell contraction. Protein kinase $\mathrm{C}$ activation, on the other hand, is associated with stimulation of cellular proliferation and hypertrophy, as well as inhibition of apoptosis.

While the vasoactive and proliferative effects of stimulation of $\mathrm{ET}_{\mathrm{A}}$ receptors are well established, the role of $\mathrm{ET}_{\mathrm{B}}$ receptors is more controversial. $\mathrm{ET}_{\mathrm{B}}$ receptor activation promotes vasodilatation via induction of nitric oxide and prostacyclin release, and is also associated with negative feedback in ET-1 synthesis. $\mathrm{ET}_{\mathrm{B}}$ receptors are also believed to be responsible for the clearance of ET-1. However, these actions are attributed to $\mathrm{ET}_{\mathrm{B}}$ receptors in endothelial cells, while the stimulation of the same receptors in smooth muscle cells is associated with vasoconstriction. In humans, it has been demonstrated that the specific stimulation of $\mathrm{ET}_{\mathrm{B}}$ receptors causes vasoconstriction, proliferation of pulmonary artery smooth muscle cells, and increased collagen production. ${ }^{20}$

Dual endothelin receptor blockade has demonstrated effectiveness in preclinical studies using experimental models of pulmonary hypertension. In a monocrotalin rat model of disease, administration of endothelin receptor blockers prevented development of pulmonary hypertension 


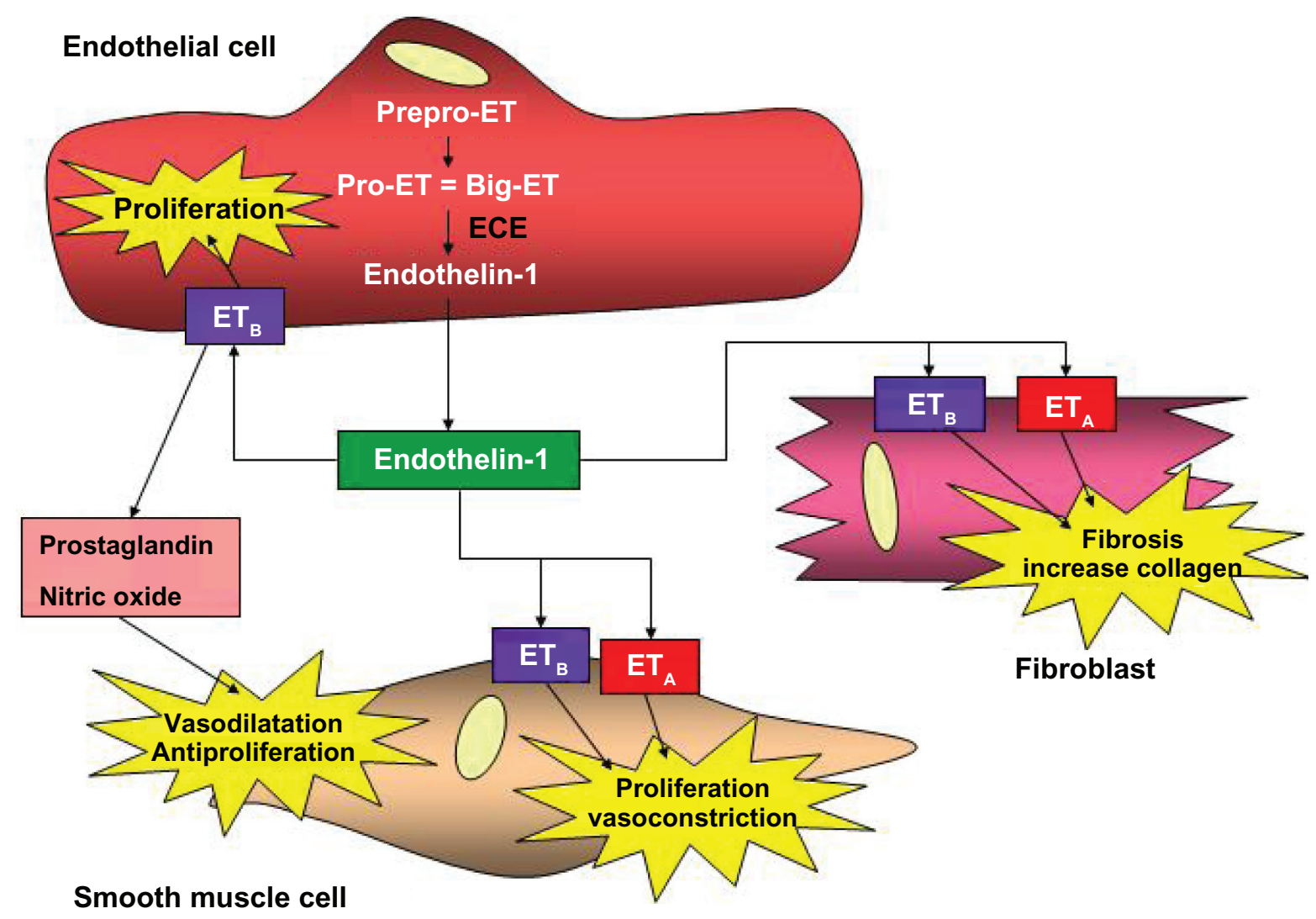

Figure I Endothelin production and action in pulmonary hypertension.

Abbreviations: prepro-ET, preproendothelin; pro-ET, proendothelin; big-ET, bigendothelin; $E C E$, endothelin-converting enzyme; $\mathrm{ET}_{\mathrm{A}}$, endothelin receptor $\mathrm{A}$; $\mathrm{ET}_{\mathrm{B}}$, endothelin receptor $\mathrm{B}$.

and right ventricular hypertrophy. ${ }^{21,22}$ In a study by Chen et al, an endothelin receptor antagonist was given after rats had developed pulmonary hypertension, and regression of pulmonary wall thickness and right ventricular hypertrophy was observed with treatment. In summary, these experimental studies demonstrated that blockade of endothelin receptors could prevent induction of pulmonary hypertension and could improve hemodynamics and ventricular remodeling. ${ }^{23}$

Favorable results in animal models and demonstration of increased ET-1 levels in patients with PAH led to evaluation of endothelin receptor blockade in patients with pulmonary hypertension. Currently, there are three endothelin receptor blockers licensed for clinical use, ie, bosentan, a nonselective $\mathrm{ET}_{\mathrm{A}} / \mathrm{ET}_{\mathrm{B}}$ receptor antagonist (dual receptor blockade), and sitaxsentan and ambrisentan, both selective $\mathrm{ET}_{\mathrm{A}}$ antagonists.

The effect of endothelin receptor blockade on ET-1 serum levels was studied. Administration of bosentan did not increase ET-1 levels in normal individuals. In patients with pulmonary hypertension, however, the baseline levels of ET-1, which were already increased compared with placebo, increased even further in the 24 hours after administration of bosentan. The peak occurred at $7.4 \pm 2.1$ hours, and the mean change in ET-1 concentration at peak was $81 \pm 11 \%{ }^{19,24}$ When patients were re-evaluated after four weeks of bosentan therapy, it was demonstrated that patients had different outcomes according to the percent change in endothelin levels 24 hours after the administration of bosentan. The group with the higher change demonstrated a significant increase in functional class and a significant decrease in brain natriuretic peptide levels when compared with the group with the lower change. Thus, the percent change of ET-1 levels in the 24 hours after administration of bosentan might predict responsiveness to chronic bosentan treatment. This transient increase in ET-1 levels after administration of bosentan is considered to be related to $\mathrm{ET}_{\mathrm{B}}$ receptor blockade, which is involved in ET-1 clearance.

Some experimental studies have demonstrated a benefit of dual receptor blockade as compared with selective blockade. In a study by Salani et al, blockade of $\mathrm{ET}_{\mathrm{A}}$ receptors led to a reduction in endothelial cell migration of approximately $25 \%$, but the addition of $\mathrm{ET}_{\mathrm{B}}$ receptor antagonist determined a higher inhibition of cell migration, increasing it to $50 \%{ }^{8}$ Furthermore, Davie et al demonstrated that when 
pulmonary artery smooth muscle cells were stimulated with ET-1, blocking of $\mathrm{ET}_{\mathrm{A}}$ receptors led to a reduction in cellular proliferation, and also showed that blocking both types of receptors reduced cell proliferation even further. ${ }^{20}$ Using a monocrotalin rat model of disease, Jasmin et al compared the action of a nonselective $\mathrm{ET}_{\mathrm{A}} / \mathrm{ET}_{\mathrm{B}}$ receptor antagonist with a selective $\mathrm{ET}_{\mathrm{A}}$ receptor antagonist. ${ }^{25}$ The administration of both antagonists lead to similar improvements in hemodynamic indices. However, only dual blockade demonstrated a significant reduction in right ventricular hypertrophy, an increase in systemic arterial pressure, and a decrease in mortality. These experimental studies suggest a benefit of dual receptor blockade over selective blockade.

\section{Bosentan for PAH}

The first study to confirm the hemodynamic effects of dual endothelin receptor blockade by bosentan in $\mathrm{PAH}$ patients used intravenous bosentan in increasing doses. A significant decrease of mean pulmonary arterial pressure in a dosedependent manner, together with a nonsignificant increase in cardiac output, was demonstrated. ${ }^{26}$

In a randomized, placebo-controlled trial, Channick et al demonstrated that oral bosentan conferred the same hemodynamic effects, with a decrease in mean pulmonary arterial pressure, pulmonary vascular resistance, and right atrial pressure, and without a significant decrease in systemic vascular resistance. ${ }^{27}$ After 12 weeks of treatment, there was also an increase in walking distance on the six-minute walking test (6MWD) in the treated group, while deterioration occurred in the placebo group. The treated group also had a significant improvement in New York Heart Association functional class and Borg dyspnea index, as well as an increase in time to clinical worsening. The drug was well tolerated, with an increase in liver enzymes in approximately $10 \%$ of patients that returned to normal after discontinuation of the drug. This was the first double-blind, placebo-controlled trial to demonstrate the beneficial effects of bosentan. However, the sample size was small, preventing further data analysis.

The BREATHE-1 (Bosentan Randomized trial of Endothelin Antagonist THErapy for pulmonary hypertension) trial, which included 213 patients, compared two different doses of bosentan and placebo in patients with $\mathrm{PAH}$ in functional classes III and IV. ${ }^{28}$ This study confirmed the clinical benefits of this therapy in PAH patients. The bosentan-treated group had a significant increase in 6MWD of $44 \mathrm{~m}$ and a significant decrease in the Borg dyspnea index. By contrast, there was a decrease in 6MWD and an increase in Borg dyspnea index in the placebo group.
The BREATHE-1 trial compared two different doses of bosentan, ie, $250 \mathrm{mg}$ twice daily and $125 \mathrm{mg}$ twice daily. In the group receiving $250 \mathrm{mg}$, there was a significant increase in 6MWD and improvement in functional class when compared with the $125 \mathrm{mg}$ group. However, when adverse effects were analyzed, use of $250 \mathrm{mg}$ twice daily was associated with a significant increase in liver enzymes. An increase in hepatic aminotransferase levels to more then eight times the upper limit of normal was observed in five patients from the $250 \mathrm{mg}$ group and in two patients from the $125 \mathrm{mg}$ group. In spite of the better clinical outcomes with $250 \mathrm{mg}$ twice daily, the dose of $125 \mathrm{mg}$ is thus the dose recommended in order to reduce the risk of hepatic impairment. ${ }^{28}$

A subsequent study found that bosentan also led to improvement in quality of life as assessed by the SF-36 health-related quality of life questionnaire, and reductions in NT-proBNP (NT-probrain natriuretic peptide) levels after 16 weeks of treatment. ${ }^{29}$

Although the hemodynamic, clinical, and functional benefits of bosentan for PAH were confirmed in the previously mentioned studies, data regarding the long-term effects of dual endothelin receptor blockade were still lacking. Subsequent uncontrolled studies attempted to establish the impact of bosentan on mortality in PAH. Survival of bosentan-treated patients was first compared with that of patients treated with epoprostenol, the only drug shown to increase survival in patients with PAH at that time. A retrospective study demonstrated that patients receiving bosentan had similar or increased survival, in a different analysis performed to avoid bias. ${ }^{30}$ Another study compared survival of patients who received bosentan with predicted survival according to the National Institutes of Health equation for nontreated PAH. ${ }^{31}$ Furthermore, an increase in survival was also demonstrated in patients treated with bosentan when compared with historic data. ${ }^{32,33}$

Notwithstanding the high mortality rate of untreated patients, there are numerous difficulties associated with designing studies to evaluate the effect of any specific PAH treatment on survival, from the sample size needed to the ethical impossibility of comparing an investigational therapy with placebo. Thus, almost all of the available data come from retrospective studies. Even so, the existing data seem robust enough to support the contention that dual blockade of endothelin receptors improves survival in PAH.

Improvements with bosentan treatment in $\mathrm{PAH}$ were also observed in imaging studies. Galie et at demonstrated improvements in echocardiographic variables after 16 weeks of bosentan use. ${ }^{34}$ Patients in the treated group had a significant 
decrease in right ventricular dilatation and increase in left ventricular size, stroke volume, and cardiac index when compared with the placebo group. Right ventricular ejection fraction also improved in the group treated with bosentan. In a study that compared cardiac magnetic resonance images before and after 12 months of bosentan therapy, patients who had an increase in right ventricular ejection fraction had a more pronounced increase in 6MWD. ${ }^{35}$ Patients treated with bosentan also demonstrated a trend towards increased stroke volume.

\section{Bosentan for PAH subgroups}

Treatment of PAH associated with portal hypertension (ie, portopulmonary hypertension), HIV infection, and congenital heart disease has also been evaluated in separate studies. Portopulmonary hypertension is of special concern because an increase in liver enzymes is a common adverse effect with endothelin receptor antagonist therapy. To address this problem, a study was conducted in patients with portopulmonary hypertension, in which 11 patients received bosentan and were followed for a period of 12 months. ${ }^{36}$ All patients had an improvement in exercise capacity, with an increase in 6MWD and increased maximum oxygen consumption, as measured by cardiopulmonary exercise testing. Six of the 11 patients had improvement in functional class. Hemodynamic profile also improved overall, with a significant increase in cardiac index and stroke volume and a concomitant decrease in pulmonary vascular resistance. Treatment with bosentan was well tolerated with no liver toxicity. This study demonstrated that bosentan may be an effective and safe therapeutic alternative for patients with portopulmonary hypertension.

For patients with PAH associated with Eisenmenger syndrome, results from a multicenter, randomized, placebocontrolled trial also demonstrated the efficacy of bosentan. ${ }^{37}$ In this study, 37 patients receiving bosentan were compared with 17 receiving placebo, with hemodynamic and functional data evaluated pre- and post-treatment. Patients treated with bosentan did not show a reduction in oxygen saturation, confirming that bosentan does not impact systemic arterial oxygen levels in this population. There was a significant reduction in mean pulmonary arterial pressure and pulmonary vascular resistance, although a concomitant reduction in mean systemic arterial pressure was also observed. The 6MWD significantly increased in the treated group. Treatment was well tolerated, and bosentan is now approved for treatment of PAH in patients with Eisenmenger syndrome.

The use of bosentan was also demonstrated to be beneficial for patients with PAH associated with HIV infection. In a recently published study, improvement in hemodynamics, quality of life, functional class, and 6MWD were reported in 20 patients with HIV-associated PAH. ${ }^{38}$ These favorable results were sustained six months after initiation of treatment, and therapy was well tolerated despite coadministration of antiretroviral drugs.

\section{Bosentan for early-stage PAH}

Recently, the benefits of bosentan for patients with less severe PAH were demonstrated in the EARLY study. ${ }^{39}$ This study was the first one to evaluate a group of exclusively functional class II PAH patients. Previous studies, including those reporting impact of drugs from other therapeutic classes, have generally included patients in functional class III and IV. The results of the EARLY study demonstrated that bosentan led to a reduction in pulmonary vascular resistance and to a delay in time to clinical worsening, with lower incidence of worsening functional class. There was no significant difference in $6 \mathrm{MWD}$, but this can be explained by the fact that patients were less symptomatic and walked more at baseline. Moreover, the placebo-treated group showed worsening of pulmonary vascular resistance and a shorter time to clinical deterioration. These observations were of major significance because, for the first time in a controlled clinical study, it was shown that less severe PAH patients do progress over time, and early interventions with bosentan partially prevented such deteriorations.

\section{Combination therapy in PAH}

Because other classes of drugs approved for treatment of PAH act on different pathways of the disease, the rationale exists for a treatment approach combining different classes of drugs. ${ }^{40}$ A number of case reports/series have demonstrated clinical response and tolerability with combination therapy. In this regard, the use of bosentan was studied in association with other pulmonary hypertension-specific medications in randomized trials. ${ }^{41}$

In a study done in patients initiating epoprostenol treatment, two groups were randomized, one to receive epoprostenol and placebo, and the other to receive epoprostenol and bosentan. ${ }^{42}$ In this study, there was a trend towards a greater hemodynamic and functional response with the combined approach, but the improvements were not statistically significant. The combination therapy was well tolerated, and even led to a decrease in the adverse effects of epoprostenol. There was less systemic hypotension in the group that also received bosentan than in the group that received epoprostenol therapy alone. However, the study was underpowered to demonstrate a significant treatment effect. 
Two other studies evaluated the addition of bosentan in PAH patients already receiving inhaled iloprost or oral beraprost. ${ }^{43,44}$ In both studies, the dose of prostanoid had not been changed for three months prior to inclusion in these studies, and bosentan was added as a second therapy. Combination therapy was well tolerated in both studies and an increase in 6MWD and improvement in symptoms were shown. Hoeper et al also demonstrated an increase in maximum oxygen consumption with addition of bosentan. ${ }^{43}$ Seyfarth et al followed their patients for a longer period of time and showed that the improvements were maintained after six months of combined treatment. ${ }^{44}$ They also demonstrated an improvement in the Tei index as assessed by transthoracic echocardiography, suggesting improvement in right ventricular function with addition of bosentan.

Bosentan was shown to be well tolerated and to improve exercise capacity when associated with other specific pulmonary hypertension treatments, suggesting that the theory of blocking the different pathways leading to the disease might be of benefit.

\section{Bosentan versus other specific therapies for pulmonary hypertension}

There are no adequately powered clinical studies comparing selective endothelin receptor blockade with dual blockade. In a study to confirm the efficacy and optimal dose of sitaxsentan, two different doses of sitaxsentan and bosentan (given in an open-label arm) were compared with placebo. ${ }^{45}$ The 6MWD was significantly higher in the groups that received both doses of sitaxsentan and in the bosentan group when compared with placebo. A similar effect of $100 \mathrm{mg}$ sitaxsentan and bosentan therapy with respect to exercise improvement was also suggested. Recently, an unblinded, observational study comparing bosentan and sitaxsentan was published. ${ }^{46}$ In this study, both drugs improved hemodynamics and exercise capacity, but there was no difference in the size of effect of the two agents regarding hemodynamic measures, 6MWD, or brain natriuretic peptide levels. Thus, neither sitaxsentan nor bosentan appeared to be superior.

In terms of safety, one study demonstrated that ambrisentan was safe when given to patients who had been previously treated with bosentan or sitaxsentan, and treatment was stopped because of a significant increase in serum aminotransferase levels. Thirty-six patients received ambrisentan, and none had to discontinue therapy because of an abnormal liver function test. ${ }^{47}$ Only one patient had a mild increase in serum aminotransferase levels that required a temporary dose reduction. The dose of ambrisentan was subsequently uptitrated and no further notable increase in serum aminotransferase levels occurred.

Few studies have compared bosentan with other specific treatment for pulmonary hypertension. Bosentan was compared with phospodiesterase-5 inhibitor treatment, ie, sildenafil, in the SERAPH (Sildenafil versus Endothelin Receptor Antagonist for Pulmonary Hypertension) study. ${ }^{48}$ In this study, two groups were randomized to receive either bosentan or sildenafil for 16 weeks. There was a significant increase in Cardiac Index and 6MWD in the whole study population. However, only the group that received sildenafil had a significant reduction in right ventricular mass and in brain natriuretic peptide levels, but there were no significant differences between the two treatment groups in any endpoint when analyzed by intention to treat.

In conclusion, until now there are no sufficiently powered studies comparing bosentan with other endothelin receptor antagonists or with other specific therapies for pulmonary hypertension. In terms of safety, ambrisentan may be less hepatotoxic.

\section{Bosentan for pulmonary hypertension caused by lung disease}

Bosentan was also evaluated in pulmonary hypertension associated with chronic obstructive pulmonary disease. In a study by Stolz et al patients with nonsevere pulmonary hypertension were randomized to receive placebo or bosentan in addition to conventional treatment for chronic obstructive pulmonary disease. ${ }^{49}$ After 12 weeks, patients receiving bosentan presented with decreases in arterial oxygen levels and in 6MWD, as well as a worsening in quality of life, implying that there were no benefits with treatment. The study did not evaluate patients by right heart catheterization, and therefore a final conclusion is difficult to make. ${ }^{50}$ Another study with chronic obstructive pulmonary disease patients randomized 32 patients, who still had pulmonary hypertension after a period of oxygen therapy, to receive placebo or bosentan. ${ }^{51}$ Treatment with bosentan led to a significant decrease in mean pulmonary arterial pressure and pulmonary vascular resistance, with an increase in 6MWD. There was no difference in arterial oxygen pressure levels with treatment. This study had a positive result and patients were evaluated with right heart catheterization, but it was not blinded and, again, final conclusions are difficult to make. Therefore, until now, there are insufficient data to support the use of bosentan in patients with pulmonary hypertension proportional to chronic obstructive pulmonary disease severity. Further studies are needed to clarify this issue. 


\section{Trial in chronic thromboembolic pulmonary hypertension}

In addition to treatment of $\mathrm{PAH}$, endothelin receptor blockade has been studied in chronic thromboembolic pulmonary hypertension, for which the gold standard treatment is thromboendarterectomy whenever possible. However, surgery is not indicated in cases of predominant distal obstruction of the pulmonary arteries by organized thrombus, while others are turned down for surgery on the basis of comorbidities. Furthermore, some patients demonstrate residual pulmonary hypertension after surgery. Survival in such instances is dramatically reduced, and studies have accordingly been undertaken in order to evaluate the use of specific pulmonary hypertension therapies for these patients. Hoper et al performed a pilot study in 19 patients with nonoperable chronic thromboembolic pulmonary hypertension. ${ }^{52}$ Three months after treatment with bosentan, these patients had an improvement in hemodynamic measurements (significant reduction in pulmonary vascular resistance and increase in cardiac output), improvement in exercise capacity (increase in 6MWD), and a decrease in NT-proBNP. The medication was well tolerated, but an increase in the dose of oral anticoagulant was needed in most cases. Bonderman et al evaluated the same type of patients, but with a larger population $(\mathrm{n}=33)$, and followed the patients for a longer time period (six months). ${ }^{53}$ Results from this study confirmed an increase in 6MWD and reduction in NT-proBNP levels, and also showed a significant improvement in functional class. The drug was again well tolerated, with no cases of increased liver enzymes. Vassallo et al also studied patients with inoperable chronic thromboembolic pulmonary hypertension, but compared bosentan with conventional therapy. ${ }^{54}$ The results confirmed a significant improvement in exercise capacity, functional class, and Borg dyspnea index in the group that received bosentan.

The BENEFIT (Bosentan Effects in iNopErable Forms of chronIc Thromboembolic pulmonary hypertension) study is, however, the only multicenter, randomized, placebocontrolled trial that examined the use of medical therapy (bosentan) for chronic thromboembolic pulmonary hypertension, either not treated by surgery or with persistence of pulmonary hypertension postsurgery. ${ }^{55}$ In this trial, 77 patients received bosentan and 80 patients received placebo. Hemodynamic improvement, with reduction in pulmonary vascular resistance and increase in cardiac index, and improvement in NT-proBNP levels and Borg dyspnea index, were demonstrated in the treatment group. Despite that, no significant increase in 6MWD or improvement in functional class or time to clinical worsening was observed. Thus, the recommendations of the most recent World Symposium on Pulmonary Hypertension, held in Dana Point in 2008, are that more studies are needed to confirm the clinical benefit of specific medical therapy for this group of patients. ${ }^{56}$

\section{Summary}

Dual endothelin receptor blockade using bosentan leads to improvement in hemodynamic profile, functional class,

Table 2 Clinical trials using bosentan in pulmonary arterial hypertension and chronic thromboembolic pulmonary hypertension

\begin{tabular}{|c|c|c|c|c|}
\hline Trial & Study design & Population & Results & Reference \\
\hline BREATHE-I & $\begin{array}{l}\text { Bosentan } 125 \mathrm{mg} \text { and } 250 \mathrm{mg} \text { versus } \\
\text { placebo }\end{array}$ & $\mathrm{PAH}$ & $\begin{array}{l}\text { Increase in 6MWD } \\
\text { Increase in time to clinical worsening }\end{array}$ & Rubin et $\mathrm{al}^{28}$ \\
\hline BREATHE-2 & $\begin{array}{l}\text { Bosentan combined with } \\
\text { epoprostenol versus epoprosteno } \\
\text { and placebo }\end{array}$ & PAH & $\begin{array}{l}\text { Trend towards clinical and } \\
\text { hemodynamic improvements }\end{array}$ & Austin et a $\mathrm{l}^{41}$ \\
\hline BREATHE-4 & Bosentan & $\begin{array}{l}\text { HIV-infected patients } \\
\text { with PAH }\end{array}$ & $\begin{array}{l}\text { Increase in 6MWD } \\
\text { Improvement in NYHA functional } \\
\text { class and quality of life } \\
\text { Hemodynamic improvement }\end{array}$ & Sitbon et a $1^{38}$ \\
\hline BREATHE-5 & Bosentan versus placebo & $\begin{array}{l}\text { Eisenmenger } \\
\text { syndrome }\end{array}$ & $\begin{array}{l}\text { No worsening of oxygen saturation } \\
\text { Hemodynamic improvement } \\
\text { Increase in exercise capacity }\end{array}$ & Galie et $\mathrm{a}^{37}$ \\
\hline EARLY study & Bosentan versus placebo & $\begin{array}{l}\text { PAH WHO } \\
\text { functional class II }\end{array}$ & $\begin{array}{l}\text { Hemodynamic improvement } \\
\text { Trend towards exercise capacity } \\
\text { improvement }\end{array}$ & Galie et $\mathrm{a}^{39}$ \\
\hline BENEFIT & Bosentan versus placebo & $\begin{array}{l}\text { CTEPH } \\
\text { nonoperable or persistent } \\
\text { or recurrent } \mathrm{PH} \text { after PEA }\end{array}$ & $\begin{array}{l}\text { Hemodynamic improvement } \\
\text { Trend towards improvement } \\
\text { in 6MWD }\end{array}$ & Jais et $\mathrm{al}^{55}$ \\
\hline
\end{tabular}

Abbreviations: BREATHE, Bosentan Randomized trial of Endothelin Antagonist THErapy for pulmonary hypertension; BENEFIT, Bosentan Effects in iNopErable Forms of chronlc Thromboembolic pulmonary hypertension; CTEPH, chronic thromboembolic pulmonary hypertension; 6MWD, six-minute walking distance; WHO, World Health Organization; PH, pulmonary hypertension; PAH, pulmonary arterial hypertension; HIV, human immunodeficiency virus; NYHA, New York Heart Association. 
and exercise capacity, and may increase survival in patients with PAH. Benefits were shown in the different subgroups of PAH and might be beneficial even for early-stage disease (Table 2). Treatment with bosentan has been shown to be safe and well tolerated, even when combined with other specific PAH therapies. Bosentan was the first oral treatment approved for the treatment of PAH and is recommended, among other drugs, in international guidelines as first-line therapy for this disease.

\section{Disclosure}

The authors report no conflicts of interest in this work.

\section{References}

1. Galiè N, Hoeper MM, Humbert M, et al. ESC/ERS GUIDELINES. Guidelines for the diagnosis and treatment of pulmonary hypertension. Eur Respir J. 2009;34(6):1219-1263.

2. Simonneau G, Robbins IM, Beghetti M, et al. Updated clinical classification of pulmonary hypertension. J Am Coll Cardiol. 2009;54 (1 Suppl S):S43-S54.

3. Perro F, Dorthmüller P, Souza R, et al. Dendritic cell recruitment in lesions of human an experimental pulmonary hypertension. Eur Respir J. 2007;29(3):462-468.

4. Montani D, Souza R, Binkert C, et al. Endothelin-1/endothelin-3 ratio: A potential prognostic factor of pulmonary arterial hypertension. Chest. 2007;131(1):101-108.

5. McLaughlin VV, McGoon MD. Pulmonary arterial hypertension. Circulation. 2006;114(13):1417-1431.

6. Galie N, Manaes A, Branzi A. The endothelin system in pulmonary arterial hypertension. Cardiovasc Res. 2004;61(2):227-237.

7. Frash HF, Marshall C, Marshall BE. Endothelin-1 is elevated in monocrotaline pulmonary hypertension. Am J Physiol. 1999;276(2 Pt 1):304-310

8. Salani D, Di Castro V, Nicotra MR, et al. Role of endothelin-1 in neovascularisation of ovarian carcinoma. Am J Pathol. 2000;157(5): $1537-1547$

9. Wort SJ, Woods M, Warner TD, Evans TW, Mitchell JA. Endogenously released endothelin-1 from human pulmonary artery smooth muscle promotes cellular proliferation. Am J Respir Cell Mol Biol. 2001;25(1): 104-110.

10. Shi-Wen X, Chen Y, Denton CP, et al. Endothelin-1 promotes myofibroblast induction through the ETA receptor via a rac/phosphoinositide 3-kinase/Akt-dependent pathway and is essential for the enhanced contractile phenotype of fibrotic fibroblasts. Mol Biol Cell. 2004;15(6): 2707-2719.

11. Hocher B, Schwarz A, Fagan DA, et al. Pulmonary fibrosis and chronic lung inflammation in ET-1 transgenic mice. Am J Respir Cell Mol Biol. 2000;23(1):19-26.

12. Dupuis J, Stewart DJ, Cernacek P, Gosselin G. Human pulmonary circulation is an important site for both clearance and production of endothelin-1. Circulation. 1996;94(7):1578-1584.

13. Humbert M, Morrell NW, Archer SL, et al. Cellular and molecular pathobiology of pulmonary arterial hypertension. J Am Coll Cardiol. 2004;43(12 Suppl S):13S-24S.

14. Brunner F. Cardiac endothelin and big endothelin in right-heart hypertrophy due to monocrotaline-induced pulmonary hypertension in rat. Cardiovasc Res. 1999;44(1):197-206.

15. Giaid A, Yanagisawa M, Langleben D, et al. Expression of endothelin-1 in the lungs of patients with pulmonary hypertension. $N$ Engl $J$ Med. 1993;328(24):1732-1739.

16. Cacoub P, Dorent R, Nataf P, et al. Endothelin-1 in the lungs of patients with pulmonary hypertension. Cardiovasc Res. 1997;33(1):196-200.
17. Nootens M, Kaufmann E, Rector T, et al. Neurohormonal activation in patients with right ventricular failure from pulmonary hypertension: Relation to hemodynamic variables and endothelin levels. $J$ Am Coll Cardiol. 1995;26(7):1581-1585.

18. Yoshibayashi M, Nishioka K, Nakao K, et al. Plasma endothelin concentrations in patients with pulmonary hypertension associated with congenital heart defects. Evidence for increased production of endothelin in pulmonary circulation. Circulation. 1991;84(6): 2280-2285.

19. Hiramoto Y, Shioyama W, Kuroda T, et al. Effect of bosentan on plasma endothelin-1 concentration in patients with pulmonary arterial hypertension. Circ J. 2007;71(3):367-369.

20. Davie N, Haleen SJ, Upton PD, et al. ET(A) and ET(B) receptors modulate the proliferation of human pulmonary artery smooth muscle cells. Am J Respir Crit Care Med. 2002;165(3):398-405.

21. Brunner F, Wölkart G, Haleen S. Defective intracellular calcium handling in monocrotaline-induced right ventricular hypertrophy: Protective effect of long-term endothelin-A receptor blockade with 2-benzo[1,3]dioxol-5-yl-3-benzyl-4-(4-methoxy-phenyl-)-4-oxobut2-enoate-sodium (PD 155080). J Pharmacol Exp Ther. 2002;300(2): 442-449.

22. Miyauchi T, Yorikane R, Sakai S, et al. Contribution of endogenous endothelin-1 to the progression of cardiopulmonary alterations in rats with monocrotaline-induced pulmonary hypertension. Circ Res. 1993;73(5):887-889.

23. Chen SJ, Chen YF, Opgenorth TJ, et al. The orally active nonpeptide endothelin A-receptor antagonist A-127722 prevents and reverses hypoxia-induced pulmonary hypertension and pulmonary vascular remodelling in Sprague-Dawley rats. J Cardiovasc Pharmacol. 1997;29(6):713-725.

24. Hiramoto Y, Shioyama W, Higuchi K. Clinical significance of plasma endothelin-1 level after bosentan administration in pulmonary arterial hypertension. J Cardiol. 2009;53(3):374-380.

25. Jasmin JF, Lucas M, Cernacek P, Dupuis J. Effectiveness of a nonselective ETA/B and selective ETA antagonist in rats with monocrotaline-induced pulmonary hypertension. Circulation. 2001;103(2): 314-318.

26. Williamson DJ, Wallman LL, Jones R, et al. Hemodynamic effects of bosentan, an endothelin receptor antagonist, in patients with pulmonary hypertension. Circulation. 2000;102(4):411-418.

27. Channick RN, Simonneau G, Sitbon O, et al. Effects of the dual endothelin-receptor antagonist bosentan in patients with pulmonary hypertension: A randomised placebo-control study. Lancet. 2001;358(9288):1119-1123.

28. Rubin LJ, Badesch DB, Barst RJ, et al. Bosentan therapy for pulmonary arterial hypertension. $N$ Engl J Med. 2002;346(12):896-903.

29. Souza R, Jardim C, Martins B, et al. Effect of bosentan treatment on surrogate markers in pulmonary arterial hypertension. Curr Med Res Opin. 2005;21(6):907-911.

30. Sitbon O, McLaughlin VV, Badesch DB, et al. Survival in patients with class III idiopathic pulmonary arterial hypertension treated with first line oral bosentan compared with an historical cohort of patients started on intravenous epoprostenol. Thorax. 2005;60(12):1025-1030.

31. McLaughlin VV, Sitbon O, Badesch DB, et al. Survival with firstline bosentan in patients with primary pulmonary hypertension. Eur Resp J. 2005;25(2):244-249.

32. Williams MH, Das C, Handler CE, et al. Systemic sclerosis associated pulmonary hypertension: Improved survival in the current era. Heart. 2006;92(7):926-932.

33. Denton CP, Pope JE, Peter HH, et al. Long-term effects of bosentan on quality of life, survival, safety and tolerability in pulmonary arterial hypertension related to connective tissue diseases. Ann Rheum Dis. 2008;67(9):1222-1228.

34. Galiè N, Hinderliter AL, Torbicki A, et al. Effects of the oral endothelin-receptor antagonist bosentan on echocardiographic and Doppler measures in patients with pulmonary arterial hypertension. $J$ Am Coll Cardiol. 2003;41(8):1380-1386. 
35. Chin KM, Kingman M, Lemos JA, et al. Changes in right ventricular structure and function assessed using cardiar magnetic resonance imaging in bosentan-treated patients with pulmonary arterial hypertension. Am J Cardiol. 2008;101(11):1669-1672.

36. Hoeper MM, Halank M, Marx C, et al. Bosentan therapy for portopulmonary hypertension. Eur Respir J. 2005;25(3):502-508.

37. Galie N, Beghetti M, Gatzoulis MA, et al. Bosentan therapy in patients with Eisenmenger syndrome: A multicenter, double-blind, randomized, placebo-controlled study. Circulation. 2006;114(1):48-54.

38. Sitbon O, Gressin V, Speich R, et al. Bosentan for the treatment of human immunodeficiency virus-associated pulmonary arterial hypertension. Am J Respir Crit Care Med. 2004;170(11):1212-1217.

39. Galie N, Rubin LJ, Hoeper MM, et al. Treatment of patients with mildly symptomatic pulmonary arterial hypertension with bosentan (EARLY study): A double-blind, randomised controlled trial. Lancet. 2008;37(1):2093-2100.

40. O'Callaghan D, Gaine S. Combination therapy and new types of agents for pulmonary hypertension. Clin Chest Med. 2007;28(1):169-185.

41. Austin MJ, McDougall NI, Wendon JA, et al. Safety and efficacy of combined use of sildenafil, bosentan, and iloprost before and after liver transplantation in severe portopulmonary hypertension. Liver Transpl. 2008;14(3):287-291.

42. Humbert M, Barst RJ, Robbins IM, et al. Combination of bosentan with epoprostenol in pulmonary arterial hypertension: BREATHE-2. Eur Respir J. 2004;24(3):353-359.

43. Hoeper MM, Taha N, Bekjarova A, Gatzke R, Spiekerkoetter E. Bosentan treatment in patients with primary pulmonary hypertension receiving nonparenteral prostanoids. Eur Respir J. 2003;22(2):330-334.

44. Seyfarth HJ, Pankau H, Hammerschidt S, Schauer J, Wirtz H, Winkler J. Bosentan improves exercise tolerance and Tei index in patients with pulmonary hypertension and prostanoids treatment. Chest. 2005;128(2): 709-713.

45. Barst RJ, Langleben D, Badesch D, et al. Treatment of pulmonary arterial hypertension with the selective endothelin-A receptor antagonist sitaxsentan. J Am Coll Cardiol. 2006;47(10):2049-2056.
46. Valerio CJ, Handler CE, Kabunga P, et al. Clinical experience with bosentan and sitaxentan in connective tissue disease-associated pulmonary arterial hypertension. Rheumatology. Jul 30, 2010. [Epub ahead of print].

47. McGoon MD, Frost AE, Oudiz RJ, et al. Ambrisentan therapy in patients with pulmonary arterial hypertension who discontinued bosentan or sitaxsentan due to liver function test abnormalities. Chest. 2009;135(1): 122-129.

48. Wilkins MR, Paul GA, Strange JW, et al. Sildenafil versus endothelin receptor antagonist for pulmonary hypertension (SERAPH) study. Am J Resp Crit Care Med. 2005;171(11):1292-1297.

49. Stolz D, Rasch H, Linka A, et al. A randomised, controlled trial of bosentan in severe COPD. Eur Respir J. 2008;32(3):619-628.

50. Jardim C, Souza R. Pulmonary hypertension therapy and COPD: Still many questions to be answered. Eur Respir J. 2009;33(2):449.

51. Valerio G, Bracciale P, Grazia D'Agostino A. Effect of bosentan upon pulmonary hypertension in chronic obstructive pulmonary disease. Ther Adv Respir Dis. 2009;3(1):15-21.

52. Hoper MM, Kramm T, Wilkens H, et al. Bosentan therapy for inoperable chronic thromboembolic pulmonary hypertension. Chest. 2005;128(4): 2363-2367.

53. Bonderman D, Nowotny R, Sajer-Skoro N, et al. Bosentan therapy for inoperable chronic thromboembolic pulmonary hypertension. Chest. 2005;128(4):2599-2603.

54. Vassallo FG, Kodric M, Scarduelli C, et al. Bosentan for patients with chronic thromboembolic pulmonary hypertension. Eur J Intern Med. 2009;20(1):24-29.

55. Jaïs X, D'Armini AM, Jansa P, et al. Bosentan for treatment of inoperable chronic thromboembolic pulmonary hypertension. J Am Coll Cardiol. 2008;52(25):2127-2134.

56. Barst RJ, Gibbs JS, Ghofrani HA, et al. Updated evidence-based treatment algorithm in pulmonary arterial hypertension. J Am Coll Cardiol. 2009;54(1 Suppl):S78-S84
Journal of Receptor, Ligand and Channel Research

\section{Publish your work in this journal}

The Journal of Receptor, Ligand and Channel Research is an international, peer-reviewed, open access, online journal. The journal welcomes laboratory and clinical findings in the fields of biological receptors, ligands, channel and signal transduction research including: receptors and signalling; ligands; transporters, pores and channels; binding and activation; receptor

\section{Dovepress}

regulation; role of receptors in diseases and their treatment; molecular basis of membrane structure and functions; molecular models of membranes. The manuscript management system is completely online and includes a very quick and fair peer-review system. Visit http://www.dovepress.com/ testimonials.php to read real quotes from published authors. 